http://jmscr.igmpublication.org/home/ ISSN (e)-2347-176x ISSN (p) 2455-0450

crossref DOI: https://dx.doi.org/10.18535/jmscr/v10i1.03

Journal Of Medical Science And Clinical Research

\title{
Correlation between Glycosylated Haemoglobin in Type 2 Diabetes Mellitus and Diabetic Retinopathy
}

\author{
Authors \\ Dr Vinayak Ganesh Bhat MD ${ }^{1}$, Dr Rajkumar Patra MS $^{2^{*}}$ \\ ${ }^{1}$ Assistant Professor, Department of Biochemistry, Maharajah's Institute of Medical Sciences, Nellimarla, \\ Vizianagaram, Andhra Pradesh, India \\ ${ }^{2}$ Assistant Professor, Department of Ophthalmology, Maharajah's Institute of Medical Sciences, Nellimarla, \\ Vizianagaram, Andhra Pradesh, India \\ *Corresponding Author \\ Dr Rajkumar Patra MS
}

Assistant Professor, Department of Ophthalmology, Maharajah's Institute of Medical Sciences, Nellimarla, Vizianagaram, Andhra Pradesh, India.

\begin{abstract}
Introduction: Diabetic Retinopathy is one of the major causes of visual impairment and blindness in Indians suffering from Diabetes mellitus. Early detection and treatment are the key to stop its progression. Onset and progression of Diabetic Retinopathy can be assessed by regular HbAlc tests in every three months, Duration of diabetes, Hypertension, Hypercholesterolemia. This study assess association between HbAlc levels and severity of Retinopathy.

Materials and Methods: this was a progressive study conducted in Maharajah's Institute of Medical Sciences, Vizianagaram, Andhra Pradesh over a period of 1 year. Total 100 patients suffering from Type 2 diabetes mellitus and visiting institution were included in this study. HbAlc, Fasting and post prandial blood glucose, lipid profile were tested in all the subjects. Ophthalmological fundus examination was done using slit lamp biomicroscopy and indirect ophthalmoscopy in all patients. Patients were followed up for 1 year for progression of disease.

Results: there was a strong association between high and uncontrolled levels of HbAlc and severity of Diabetic retinopathy. A statistically significant association was found ( $p<0.01)$. however, retinopathy was not related to HbAlc alone. There were other risk factors like duration of diabetes, Hypercholesterolemia which also contributed to the progression.

Conclusion: HbAlc levels > 7.0\% was significantly associated with Diabetic Retinopathy. The severity of retinopathy was dependent on Blood glucose levels and duration of diabetes. Strict control of HbAlc levels is crucial to prevent diabetic retinopathy and its vision impairing complications.
\end{abstract}

\section{Introduction}

Diabetes mellitus is defined by World Health Organization as a metabolic disorder characterized by Chronic hyperglycemia with disturbed carbohydrate, protein and fat metabolism ${ }^{1}$. India has estimated 77 million Diabetes patients. India has $17.5 \%$ of global Diabetic patients ${ }^{2}$. Prevalence for all age groups worldwide is $2.9 \%$ expected to raise to $4.5 \%$ by year 2030. Most appropriate method to check Diabetes status is calculating 
HbA1c levels. It tells better idea about Diabetic control than Fasting and Post prandial Blood Glucose levels. Various methods have been used to screen Diabetic Retinopathy and Maculopathy which includes Direct ophthalmoscopy, Fundus camera, Optical coherence tomography (OCT) ${ }^{3}$. Criteria for diagnosing and staging Diabetic Retinopathy is given by Early Treatment Diabetic Retinopathy Study (EDTRS) ${ }^{4}$.

Association between HbA1c and different types of Diabetic Retinopathy, Maculopathy has hardly been studied. Is this study we are correlating the effect of HbA1C on different types of Retinopathy in a study conducted in Maharajah's Institute of medical Sciences, Vizianagaram, Andhra Pradesh. Advanced Glycation end products including $\mathrm{HbA1c}$, gets deposited in various areas and cause many conditions including Diabetic Retinopathy ${ }^{5}$. So, severity and duration of Diabetes in subjects without proper diabetic control is seen to be correlating to Diabetic retinopathy with increased risk. This study assesses this risk in patients visiting our medical college.

\section{Material and Methods}

\section{Sampling, Statistical Methods, Inclusion and Exclusion Criteria}

This was a Cohort study done at Maharajah's Institute of Medical Sciences, Vizianagaram, Andhra Pradesh, India, after obtaining ethics committee approval over one-year period. This study was conducted with combined work of Department of Biochemistry and Department of Ophthalmology. Institutional ethics committee approval was taken before study and written informed consent was taken from all the study participants. During each follow up visit patient underwent evaluation at both Biochemistry and Ophthalmology Department. 100 subjects from general population with findings of Diabetic Retinopathy were enumerated based on multistage random sampling, which was assessed based on their level of $\mathrm{HbA} 1 \mathrm{c}$.

Inclusion criteria included all the diabetes mellitus patients visiting OPD, both newly diagnosed and those on treatment. Their fasting blood glucose or HbA1c levels confirmed Diabetes mellitus. Patients with other morbidities like Hypertension were excluded from the study. All the selected patients with Diabetes underwent a detailed anterior segment and fundus examination.

\section{Methodology}

All the subjects of the study were tested for fasting blood glucose and HbAlc. a written informed consent was obtained from each individual prior to their participation. A detailed medical and Ophthalmic history, including duration, Treatment, other systemic illness, were taken.

Detailed Biochemical investigations was done which included Fasting and Post prandial Blood glucose, HbA1c, Total serum Cholesterol (TC), High density lipoprotein (HDL), Low density lipoprotein (LDL), Serum Triglycerides (TG), Micro and macro albuminuria.

Later they were sent to Department of Ophthalmology for a detailed Ophthalmological examination. Diabetic Retinopathy was diagnosed in the subjects as per Modified Early Treatment Diabetic Retinopathy study ${ }^{6}$.

Detailed Ophthalmological examination for both eyes were conducted including best corrected visual acuity, anterior segment slit lamp examination, gonioscopy, Intra ocular pressure measurement with the help of applanation tonometry. Pupil was dilated and Retinal examination was done with indirect Ophthalmoscopy.

\section{Results}

100 patients with Diabetes mellitus were studied. Those with Retinopathy were found to be $37 \%$. Patients were classified as those with NPDR Retinopathy, PDR Retinopathy and Maculopathy. Average HbA1c levels in severe NPDR was 6.8 (3\%). PDR was 7.4 (5\%) and Clinically significant macular edema (CSME) was 9.8 (1\%) $(\mathrm{P}=0.03)$. Retinopathy group included subjects with severe NPDR $(n=3), \operatorname{PDR}(n=5)$, Clinically 
significant macular edema $(n=1)$. Correlation between clinically significant macular edema and HbA1c was statistically significant $(\mathrm{p}<0.03)$. It was also noted during the study, Duration of Diabetes played a key role. Those with increased duration of Diabetes with uncontrolled status and newly diagnosed diabetic patients were found tobe significantly higher $\mathrm{HbA1c}$ levels compared to other patients.

Table 1: HbA1c levels and number of patients

\begin{tabular}{|l|c|c|}
\hline HbA1c & No. of patients & Percentage \\
\hline Less than 8 & 58 & $58 \%$ \\
\hline 8 to 10 & 32 & $32 \%$ \\
\hline More than 10 & 10 & $10 \%$ \\
\hline
\end{tabular}

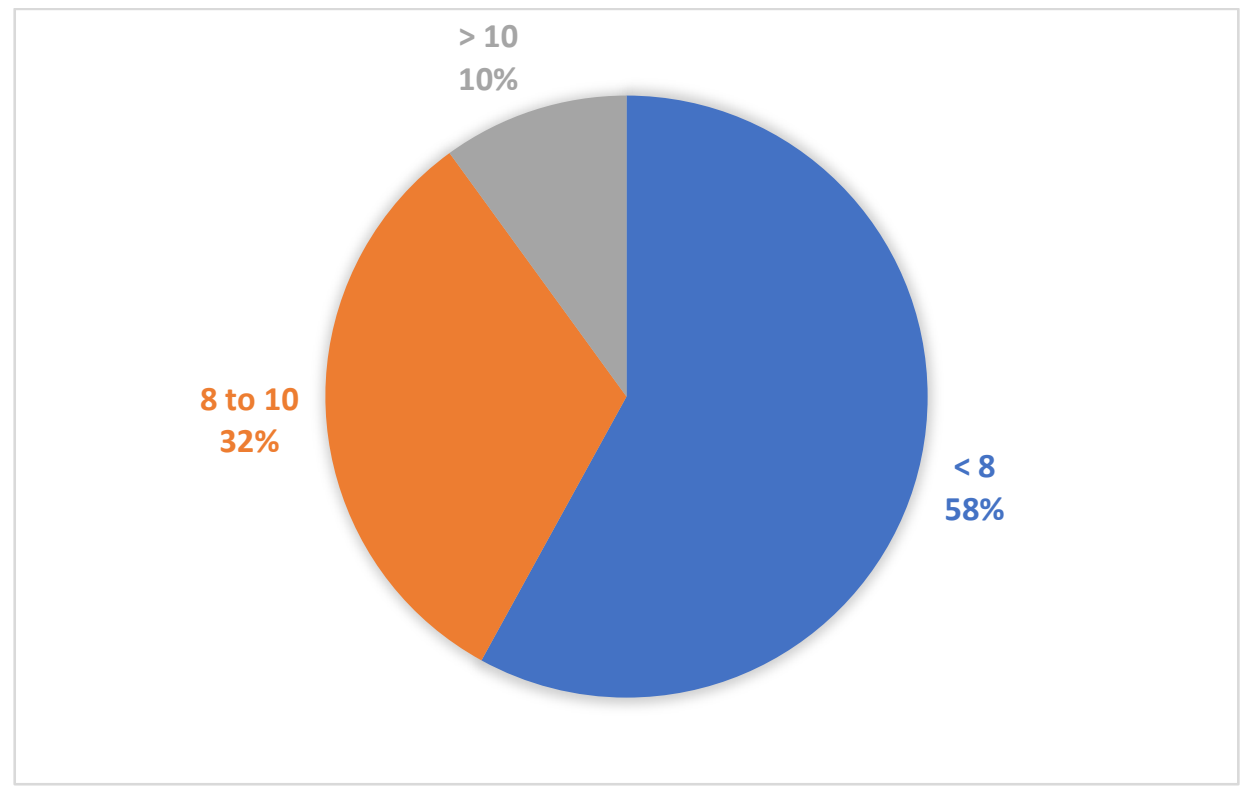

Table 2: Correlation of incidence of Retinopathy/maculopathy

\begin{tabular}{|l|c|c|}
\hline Retinopathy/Maculopathy & No. of patients & HbA1c \\
\hline NPDR & $3 \%$ & 6.8 \\
\hline PDR & $5 \%$ & 7.4 \\
\hline Maculopathy & $1 \%$ & 9.8 \\
\hline
\end{tabular}

\section{No of patients}

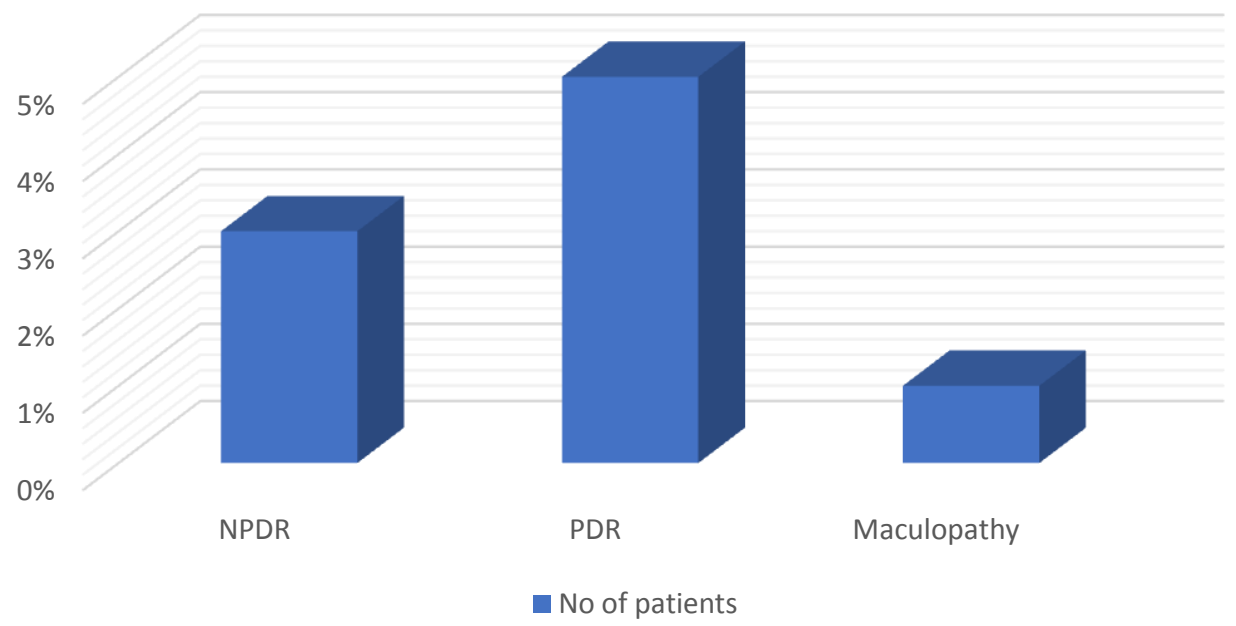




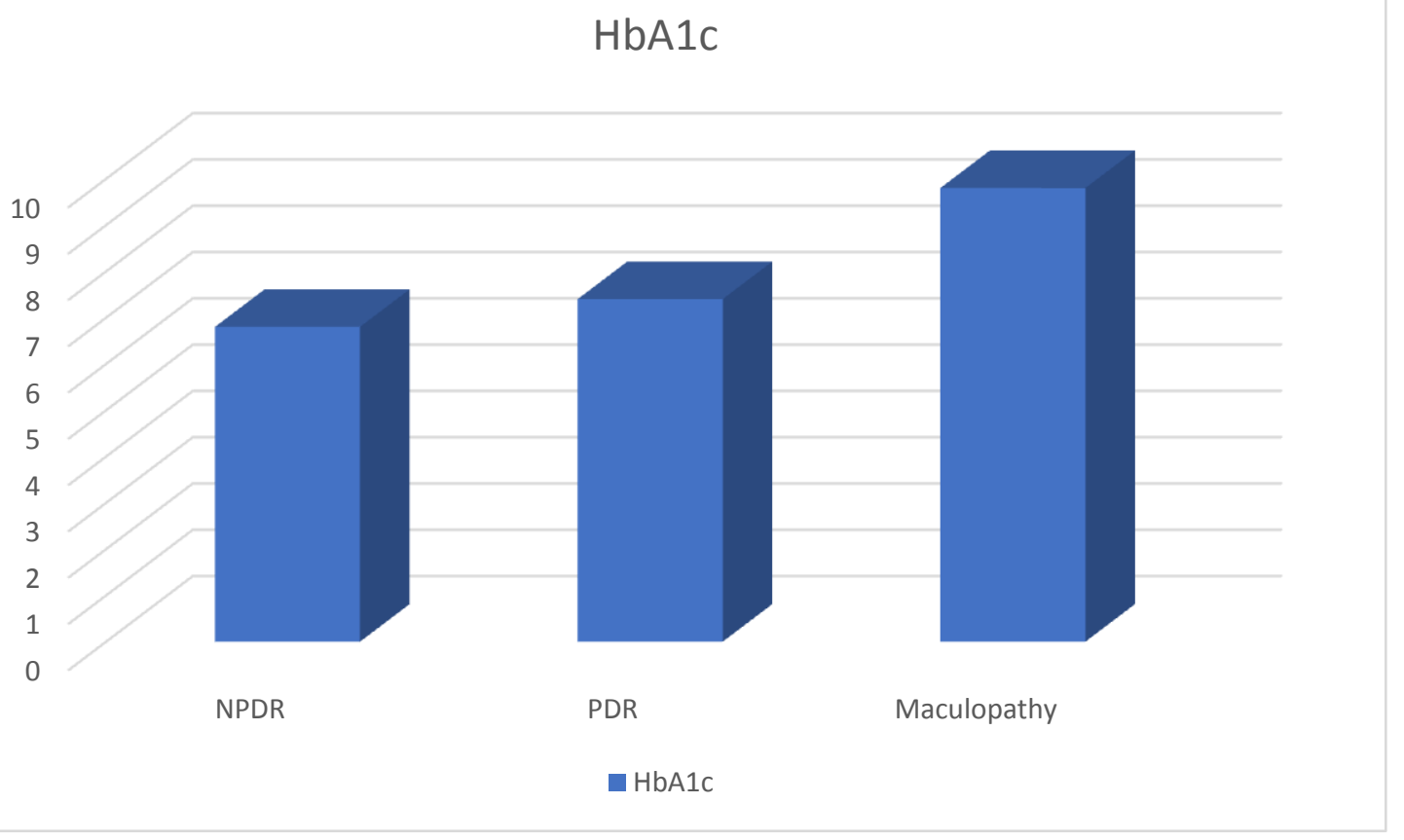

HbA1c levels was found to be statistically relevant in case of Clinically significant macular edema (CSME) ( $p=0.003)$. Distribution of Retinopathy was found to be $43 \%$ with Disease greater than 15 years, $42 \%$ with disease greater than 10 years and $15 \%$ in those who have Diabetes mellitus less than 10 years duration. Retinal detachment was also noted in 1 patient when follow-up was done after 8 months.

On final analysis, our study showed longer duration of Diabetes mellitus, male sex predominance, poor glycemic control, high HbA1c levels are important risk factors among the subjects for the progression of Diabetic Retinopathy. Patients with age between $50-60$ years was 35\%, 40 - 50 years $29 \%, 10 \%$ in extreme age group. Males were $67 \%$ compared to $33 \%$ female patients. Increased Triglycerides were seen in $27 \%$ of patients with Retinopathy.

\section{Discussion}

In recent times, Biochemistry investigative procedures have seen a drastic improvement with new innovations and developments. One of such development is HbA1c test. It tells accurately, the Diabetes status of the patient from past 3 months. Recently HbA1c test has gained importance in Diabetes treatment and also to assess onset and progression of the disease ${ }^{7}$. HbAlc when compared to measurement of glucose levels, accurately tells the level of hyperglycemia at which the prevalence of Diabetic Retinopathy increases ${ }^{8,9}$. In this study we evaluated the association of HbA1c with occurrence of Diabetic Retinopathy. There are very less studies conducted correlating this association.

Duration of diabetes mellitus is greatly associated with Retinopathy and its related complications. Even previous epidemiological studies have found similar risk factors like duration of Diabetes and higher HbA1c levels independently for Non proliferative Diabetic Retinopathy (NPDR), Macular edema and Proliferative Diabetic Retinopathy (PDR) ${ }^{10}$.

In uncontrolled Diabetes, excess Glucose present in blood and tissues react with tissue proteins to create Glycated end products and HbAlc. this keeps on forming as long as there is uncontrolled Diabetes. So strict glycemic control, is strongly associated with decreased micro vascular complications associated with Diabetes. Anita et al. studies the same association and found Advanced glycation index (AGI) to be strongly related to severity of Diabetic Retinopathy ${ }^{10}$. Similar correlation was also noted in study conducted by Priyadarshini et $\mathrm{al}^{11}$. Earlier reports 
have also proved that prevalence of Diabetic retinopathy increased significantly when $\mathrm{HbA1c}$ was noted in between $6.0 \%$ to $7.0 \%$. Further extensive studies concluded HbAlccut off as $6.5 \%$ as sufficiently sensitive parameter and specific to identify all those Diabetic patients who are at risk of developing Diabetic Retinopathy ${ }^{11}$.

Other risk factors such as Hypercholesterolemia, hypertension, Obesity and Nephropathy in patients with Diabetic Retinopathy can worsen the state of eye. So, addressing all the above-mentioned risk factors plays a key role in arresting the progression of Diabetic Retinopathy ${ }^{12}$. Extra Care should be taken in children with diabetes because they will have longer duration of diabetes ${ }^{11,13}$. Inflammation is another risk factor. Chronic inflammation sets in due to collection of Glycated end products in Retina and elsewhere. Chronic inflammation caused changes at the biochemical and molecular level causing Retinopathy and vision loss in such patients ${ }^{14}$. Its also seen that Fluctuation in plasma glucose levels causes progression of Diabetic retinopathy more than Diabetic nephropathy in Diabetic patients ${ }^{15}$.

Derangement of Serum cholesterol, low density lipoproteins, high density lipoproteins, triglycerides is seen to be associated with patients with retinopathy compared to those without Retinopathy. Its also seen in a study conducted by Amin $\mathrm{ZA}$ et $\mathrm{al}^{16}$ conducted in Pakistan population. Overall, we come to understanding that $\mathrm{HbA1c}$ levels really assesses the Diabetic status of the patients suffering from Diabetes mellitus. As duration also plays a key role in progression of diabetes, monitoring HbA1c levels for every 3 months over the course of time, will have a significant help in understanding progression of Retinopathy.

The findings of our study probably have benefit in Diabetic Retinopathy screening programs. In screening programs, Diabetes patients with HbA1c. $8.0 \%$ can be targeted for sight threatening retinopathies. Those patients with $\mathrm{HbA1c}>7.0 \%$ can be kept under regular supervision and regular fundus examination every 6 months, can help in understanding progression of Retinopathy and early intervention in arresting the progression of the disease.

\section{Conclusion}

Diabetic Retinopathy in one of the most common sight threatening complication in patients with Diabetes mellitus. Duration of Diabetes, HbA1c levels are 2 key points which help in assessing the progression of Retinopathy. Regular check up and keeping $\log$ of $\mathrm{HbA} 1 \mathrm{c}$ levels every three months along with Detailed ophthalmological examination every 6 months to one year is essential in detecting the progression of Retinopathy. Rigid control of HbA1c along with other risk factors has to be stressed. There was less awareness about the importance of $\mathrm{HbAlc}$ tests among diabetic patients who come from villages and older population compared to Urban and young population.

\section{Bibliography}

1. Babran M, Laher I. Type II Diabetes mellitus in Arabic-speaking countries. International journal of endocrinology 2012;2012.

2. Kannan, Ramya. India is home to 77 million diabetics, second highest in the world. The Hindu. ISSN 0971-751X. 2020-04-29.

3. Krishnamurti U, Steffes MW. Glycohemoglobin: a primary predictor of the development or reversal of complications of diabetes mellitus. Clin Chem. 2001;47 (7):1157-65.

4. Davis MD, Fisher MR, Gangnon RE, Barton F,Aiello LM, Chew EY, Ferris FL 3rd, Knatterud GL. Risk factors for highrisk proliferative diabetic retinopathy and severe visual loss: Early Treatment Diabetic Retinopathy Study Report \#18. Invest Ophthalmol Vis Sci. 1998 Feb; 39(2):233-52.

5. Ciulla TA, Amador AG, Zinman B. Diabetic retinopathy and diabetic macular 
edema: pathophysiology, screening, and novel therapies. Diabetes Care. 2003 Sep;26(9):2653-64.

6. Klein R, Klein BE, Magli YL, Brothers RJ, MeuerSM, Moss SE, Davis MD. An alternative method ofgrading diabetic retinopathy. Ophthalmology 1986 Sep; 93(9):1183-7.

7. Agarwal S, Raman R, Paul PG, Rani PK, Uthra S, Gayathree R, McCarty C, Kumaramanickavel G,Sharma T. Sankara Nethralaya-Diabetic Retinopathy Epidemiology and Molecular Genetic Study (SN-DREAMS1): study design and research methodology. Ophthalmic Epidemiol. 2005 Apr;12(2):143-53.

8. Tapp RJ, Tikellis G, Wong TY, Harper CA, Zimmet PZ, Shaw JE; Australian Diabetes Obesity and Lifestyle Study Group. Longitudinal association of glucose metabolism with retinopathy: results from the Australian Diabetes Obesity and Lifestyle (Aus Diab) study. Diabetes Care. $2008 \quad$ Jul; 31(7):1349-54. doi:10.2337/dc07-1707. Epub 2008 Apr 14.

9. Brown JB, Pedula KL, Summers KH. Diabetic retinopathy: contemporary prevalence in a well controlled population. Diabetes Care. 2003 Sep; 26(9):2637-42.

10. Anitha B, Sampathkumar R, Balasubramanyam M,Rema M. Advanced glycation index and its association with severity of diabetic retinopathy in type 2 diabetic subjects. J Diabetes Complications. 2008 Jul-Aug;22(4):261-6. doi:10.1016/j.jdiacomp.2007.05.005.Epub 2008 Apr 16.

11. Priyadharshini N, Annamalai R, Muthayya M.K. The relationship between blood sugar levels (glycosylated haemoglobin) and the risk of development of diabetic retinopathy. Int JMed Res Rev 2017;5(01):61-67.doi:10.17511/ijmrr.

2017.i01.09.

12. Liew G, Wong VW, Ho IV. Mini-Review: Changesin the Incidence of and Progression to Proliferative and SightThreatening Diabetic Retinopathy Over the Last30 Years. Ophthalmic Epidemiol. 2017 Jan 19: 1-8. doi:10.1080/09286586.2016.1259638.

13. Akil H, Buluş AD, Andiran N, Alp MN. Ocular manifestations of Type 1 diabetes mellitus in pediatric population. Indian $\mathbf{J}$ Ophthalmol. 2016 Sep;64(9):654- 658. doi:10.4103/0301-4738.194336.

14. Roy S, Kern TS, Song B, Stuebe C. Mechanistic Insights into Pathological Changes in the Diabetic Retina: Implications for Targetng Diabetic Retinopathy. Am J Pathol. 2017 Jan; 187(1): 9-19. doi: 10.1016/jajpath.2016.08.022.

15. Umayahara Y, Fujita Y, Watanabe H, Kasai N,Fujiki N, Hatazaki M, Koga M. Association of glycatedalbumin to HbA1c ratio with diabetic retinopathy butnot diabetic nephropathy in patients with type 2diabetes. Clin Biochem. 2016; Dec 5. pii: S0009-9120 (16)30390-3. doi: 10.1016/j.clinbiochem. 2016.11.032.

16. Amin ZA, Islam QU, Mehboob MA. Comparison of serum lipid profile in Type-2 Diabetics with and without retinopathy in Pakistani population. Pak J Med Sci. 2016 Nov-Dec;32(6):1349-1353. doi: 10.12669 /pjms. 326.11056. 